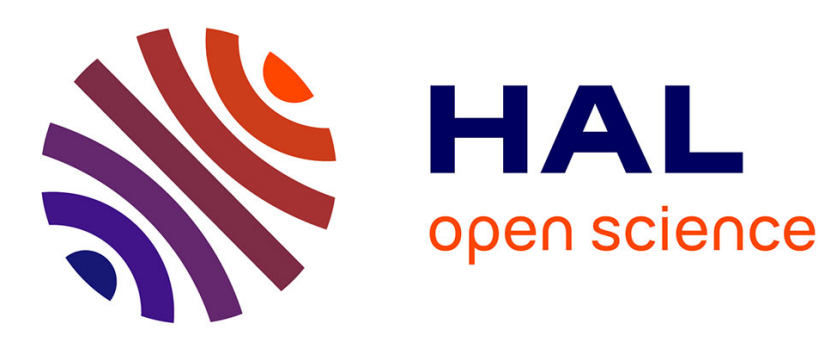

\title{
Trend Breaks in the Research and Development Process
}

Patricio Pérez, Vicente Esteve

\section{To cite this version:}

Patricio Pérez, Vicente Esteve. Trend Breaks in the Research and Development Process. Applied Economics, 2007, 39 (05), pp.663-674. 10.1080/00036840500447666 . hal-00581917

\section{HAL Id: hal-00581917 https://hal.science/hal-00581917}

Submitted on 1 Apr 2011

HAL is a multi-disciplinary open access archive for the deposit and dissemination of scientific research documents, whether they are published or not. The documents may come from teaching and research institutions in France or abroad, or from public or private research centers.
L'archive ouverte pluridisciplinaire HAL, est destinée au dépôt et à la diffusion de documents scientifiques de niveau recherche, publiés ou non, émanant des établissements d'enseignement et de recherche français ou étrangers, des laboratoires publics ou privés. 


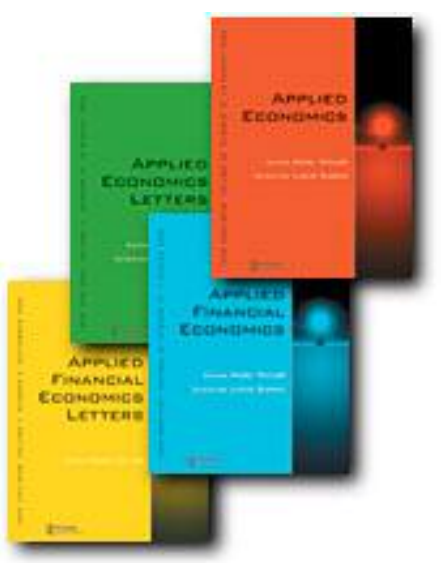

Trend Breaks in the Research and Development Process

\begin{tabular}{|c|c|}
\hline Journal: & Applied Economics \\
\hline Manuscript ID: & APE-05-0135.R1 \\
\hline Journal Selection: & Applied Economics \\
\hline $\begin{array}{r}\text { Date Submitted by the } \\
\text { Author: }\end{array}$ & 26-Oct-2005 \\
\hline JEL Code: & $\begin{array}{l}\text { O33 - Technological Change: Choices and Consequences|Diffusion } \\
\text { Processes < , O47 - Measurement of Economic Growth|Aggregate } \\
\text { Productivity < }\end{array}$ \\
\hline Keywords: & Researchers, Structural change, Idea stock \\
\hline
\end{tabular}




\section{INTRODUCTION}

Many studies have documented a slowing down of productivity growth in Organization for Economic Co-operation and Development (OECD) countries, around the early 1970s and early 1980s. This being the case, one might expect a certain synchrony between the behaviour of output per worker, on the one hand, and certain indicators of technological progress, on the other. Layton and Banerji (2003, p. 17901792) noted that cyclical co-movements of the key coincident indicators characterize business cycles. For Romer (1990), the advance of technical progress depends on the discovery of new ideas. Researchers whose work is devoted to research and development (R\&D) and idea stock activity, all other things being equal, determine total factor productivity (TFP) growth. By linking idea stock with TFP, Jones $(1995,2002)$ transformed the function of production for ideas into a technical progress function.

According to Keely and Quah (1998), R\&D is a readily identifiable factor input for knowledge production in many technology-driven industries. A look back over the past decades reveals a decline in R\&D growth rates that begins in the mid-1960's, "the timing" being "appropriate for declining productivity growth 5-10 years later" (Griliches 1994, p. 2). This view is strengthened by the fact that the share of gross national product (GNP) devoted to R\&D shows simultaneous signs of stagnating. As Verspagen (1996) points out, and as table 1 illustrates for the G-5, there appear to be huge differences (in terms of R\&D spending) between the OECD countries. The USA and Switzerland started out as the leading countries in this respect, but during the 1970s and 1980s certain major European nations, also accompanied by Japan, caught up.

[Insert Table 1 around here] 
In this paper, our goal is to provide a characterisation of the takeoffs and slowdowns observed in input and output measures of $R \& D$ in the United States, Germany, France and the United Kingdom. A sequential methodology is applied to test for breaks in the number of researchers and in the idea stock, which introduces the possibility of examining the long run behaviour of growth rates. The testing procedure covers the period between 1950 and 2001. The estimates bear out the perception of a slowdown in R\&D process, although they bring forward the date of change. The four countries mentioned experience a trend and level break in the researcher series for the mid-1960s, with a slight variation in break year dates. The results as a whole also corroborate the thesis of new ideas slowdown, in the middle of the 1960s (coinciding, moreover, in the United States with the first oil crisis). The United States, at the top, and Germany, at the bottom, represent the extremes in the range. Both statistical procedures allowing for two shifts and multiple structural change methods work out quite similar results.

The rest of the paper is organized as follows. The next section describes the data and discusses measurement issues. In the third section, a time frame is spelt out to detect the presence of some breaks and their impact. The fourth section focuses on the timing of the breakpoints and assesses for the economic implications. Finally, the fifth section offers some concluding remarks.

\section{DATA}

According to Romer's (1990) model, the cumulative stock of knowledge used to produce output, $A$, corresponds to the number of ideas invented over the course of the 
history until time $t$. In Jones' (2002) paper, this is the first factor on the right side of the aggregate production function:

$$
Y_{t}=A_{t}^{\sigma} K_{t}^{\alpha} H_{Y t}^{1-\alpha}
$$

where $K$ is physical capital and $H_{Y}$ is the total quantity of human capital employed to produce output. It assumes $0<\alpha<1$ and $\sigma>0$. In practice, $A_{\mathrm{t}}$ is measured as multifactor productivity in equation (1). The accounting exercise is conducted in the same spirit as Solow's classic growth accounting model. (For data sources, see Appendix A).

On the other hand, effective research effort made by a country, $H_{A}$, is the weighted sum of researchers where the weights adjust for human capital:

$$
H_{A t}=\sum h_{t}^{\theta} L_{A t}
$$

In this equation, $L_{A}$ is the number of researchers, $h$ is human capital per person and $\theta \geq$ 0 . Scientists and technicians are viewed by the OECD as the central element within the research and development system. In accordance with the observations made by Bils and Klenow (2000, p. 1162) in relation to human capital, national scientists may both speed up the adoption of technology and also be necessary for technology use.

We are well aware of the potential problems caused by possible inadequacies presented by the data used to carry out the analysis. In this respect, idea stock (the residual of the production function) measures all other sources not taken into account by the growth rates of conventional inputs (Atella and Quintieri 2001, p. 1387). On the other hand, the series for numbers of researchers appears to be more reliable, though certain considerations will have to be borne in mind (Romer 2000, p. 21). To provide a rough empirical measure of $H_{A}$, we will assume that $\theta=0$ in equation (2). Nonetheless, "measured $R \& D$ is the only data we have, and it probably represents a reasonable benchmark provided these caveats are kept in mind" (Jones 2002, p. 226). Indeed, any 
other indicator one might choose would certainly be accompanied by its own peculiar disadvantages. For example, scholars like Griliches (1990) have laboured long in their endeavours to measure patents, without coming up with any convincing outcome.

\section{THE TIME SERIES FRAMEWORK}

This section lays briefly out the model and statistical procedure, allowing for two shifts in the deterministic trend at two distinct unknown dates. The reader is referred to Perron (1989, 1997), Banarjee et al. (1992), Zivot and Andrews (1992), Lumsdaine and Papell (1997), Vogelsang and Perron (1998), Ben-David and Papell (1995, 2000) and Atkins and Chan (2004) for further details. It is possible to think of $y_{t}$ as being the sum of a deterministic component $T D$ and a stochastic component $Z_{t}$,

$$
y_{t}=T D_{t}+Z_{t},
$$

where $T D$ is linear in time $t$,

$$
T D_{t}=\mu+\beta t
$$

Once the unit root hypothesis has been rejected, the analysis focuses on the timing of the breakpoints and their severity. Our objective is to test for possible multiple structural changes in long-term output (logarithm of the stock of ideas and of researchers). The null hypothesis of no structural change is that $\mu$ and $\beta$ are constant over the span of the data, whereas the alternative allows for one or more simultaneous changes in both the intercept and the slope. Firstly, the null hypothesis of no structural change is tested, within a framework in which the break years are not exogenously predetermined, but where a process that endogenises the search is used. Sen $(2004, \mathrm{p}$. 2026) shows that "use of the mixed model will yield more reliable estimates of the break-date". So the test for trending data involves regressions of the following form: 


$$
y_{t}=\mu+\sum_{i=1}^{m} \theta_{i} D U_{i t}+\beta t+\sum_{i=1}^{m} \gamma_{i} D T_{i t}+\sum_{j=1}^{k} c_{j} y_{t-j}+\varepsilon_{t}
$$

The period in which a change takes place in the trend function parameters is identified as $T_{B i}$. The break dummy variables take the following values: $D U_{i t}=1$ and $D T_{i t}=t-T_{B i}$ if $t>T_{B i}, 0$ otherwise. The equation is estimated sequentially for all possible pairs $\left(T_{B l}\right.$, $T_{B 2}$ ), where $T_{B i}=2, \ldots T-1, i=1,2$, and $T$ is the number of observations after adjusting for lag length $k . C(L)$ is a lag polynomial of known order $k$.

For each choice of $T_{B i}$, the value of the lag length $k$ is established following the criterion employed by Campbell and Perron (1991). This is a recursive method, where an upper bound $k_{\max }$ is set a priori. If the last included lag is significant, choose the upper bound; otherwise, a unit reduces $k$. If there is no significant lag, set $k=0$. We set the upper bound on $k$ equal to 8 and the criterion of significance of the last lag statistic is set at 1.6 , corresponding to $10 \%$ of the asymptotic normal distribution. The $\operatorname{Sup} F_{t}$ statistic is the maximum (among all the possible trend breaks) of twice the standard $F$ statistic to test $\theta_{1}=\gamma_{1}=0$. The null hypothesis of no structural change is rejected if it exceeds the critical value.

Once $T_{B 1}$ has been fixed in the manner indicated above, the equation (5) is estimated for each potential break year $\left(T_{B 2}\right)$, calculating the statistic $\operatorname{Sup} F_{t}$ as described. The procedure now consists of testing the null hypothesis of a one-break, as against a two-break alternative, subject to the constraint that the second break be separated from the first by a gap of at least five years. The possibility of more break points may be investigated, adding additional dummy variables to the equation. In this context, slowdown is to be understood as a statistically significant negative break in the trend function of the growth process. Recession, in contrast, is defined as a severe slowdown, whereby the pre-break growth rate is positive and the post-break rate is negative (BenDavid and Papell 1998, p. 564). 
We start by estimating regressions for a flexible model, allowing for multiple breaks, both in the slope of the trend function and in the intercept. If the $D U_{i t}$ and $D T_{i t} t$ statistics are significant for a certain $T_{B i}$, we register the results of the complete model; otherwise the non-significant variable is eliminated and we proceed to re-estimate models that admit breaks in the slope $\left(\theta_{i}=0\right)$ or in the intercept $\left(\gamma_{i}=0\right)$. So how does a break in the trend function affect steady-state growth? If $y(t)$ has a stationary trend, it asymptotically approaches to a steady-state growth path. Then, using the coefficients estimated from (5), the balanced growth rates converge for each country in the final period of the sample to the constant values:

$$
\lim _{t \rightarrow \infty} \Delta y=\beta /\left(1-\sum_{j=1}^{k} c_{j}\right)
$$

or with:

$$
\lim _{t \rightarrow \infty} \Delta y=\left(\beta+\sum_{i=1}^{m} \gamma_{i}\right) /\left(1-\sum_{j=1}^{k} c_{j}\right),
$$

when the coefficients of the dummies registering the trend are included. From equations (6) and (7) we gather that a change in level $\left(\theta_{i}\right)$ has an influence on stocks (of researchers and / or ideas), but not on growth rates. Whereas a trend break $\left(\gamma_{i}\right)$, when there is stationarity, will have an impact on the steady-state growth path.

\section{TREND BREAKS AND STEADY STATE GROWTH}

The main results, obtained by applying equation (5), are presented in table 2 . In general, the data from the researcher and scientist collectives match up well with our intuition (panel A). Whilst expressing natural reservations, given a sample of this size, the process of estimation provides evidence of trend breaks. Using critical asymptotic 
values, the null hypothesis of no-break is rejected at a level of 5\% in the US and France. The decision is not so clear for Germany and Great Britain, although the value of the statistic (16.15 y 16.18) makes it possible to reject the null at a level of $10 \%$.

[Insert Table 2 around here]

It is interesting to observe the $T_{B}$ break years involved here. In all the countries, they are located around the mid-1960s: France in 1966, the United States in 1967 and Great Britain in 1968. Only Germany "jumps the gun”, its change occurring in 1963; although this is conditioned by the fact that the $\operatorname{Sup} F_{t}$ statistic proves significant at a level of $10 \%$. In all cases the estimation processes identify reductions in the trend function slope, i.e. there is a slowing-down. In the US, there is additionally a drop in the intercept or, in other words, recession. (Appendix B records the coefficients and $t$ statistics in their totality). The results suggest a high degree of coincidence in the development of the research infrastructure. At the end of the 1960s a deceleration was produced in the growth rate of this collective, anticipating the end of the "golden age" of the western economies. The results coincide with those of Ben-David et al. (2003, p. 311), whose findings are that more than half of the countries they analysed experienced one of their breaks in 1955 or later, while some did so in the 1970s. Harvey and Mills (2005, p. 174) also provide strong evidence of the existence of a common business cycle among these countries.

As well as this generalised breakdown in the second half of the 1960s, in Germany, 1989 is the epitome of another breakpoint. The series of researchers is characterised by what seems to be a peak, followed by a swift return to the growth path 
prior to the break. As for France, the series climbs a rung in 1980 and embarks on a path with a somewhat steeper slope, but not enough to imply a trend change.

The results in table 2 (panel B) are in accordance with the thesis of research intensity deceleration, between the mid-1960s and mid-1970s. Notwithstanding, the conclusions are not now as evident as those that were extracted from the researcher series. On the one hand, the null is conclusively rejected in the United States and Germany at a 5\% level of significance, in favour of the alternative of stationarity accompanied by trend break in the 1960s. But, on the other hand, the estimation processes do not permit rejection of the null hypothesis of an absence of breaks in France, and the situation in Great Britain is limited to an upwards change of level.

Figure 1 plots the logarithmic representation of the researcher and scientist series, and figure 2 does the same in relation to idea stock. In both cases, the series projected are obtained by extrapolating the first pre-break growth paths. It can be easily noted that the actual paths, marked with a continuous line, are situated significantly below the extrapolations (subsequent to the break), depicted by a broken line.

[Insert Figure 1 around here]

[Insert Figure 2 around here]

How deep do the changes go? The crisis of the 1960s signals the end of the period of high growth that followed the post-second world war period; and a return to what seems to have been the new path of long-term growth in the western economies (BenDavid et al. 2003, p. 312). All the $\gamma_{l}$, the coefficient of the dummy that registers trend change, are negative, though of a very different value. Two subgroups are easily identifiable in the sample: on one side, the US and Great Britain, with around half a 
percentage point $(\gamma=-0.6 \%)$; on the other, Germany and France, whose average is higher than one percentage point $(\gamma=-1.11 \%)$. The United States, at the top, and Germany, at the bottom, represent the extremes in the range. The United States is the only country that, as the slope falls, experiences a simultaneous drop in level $\left(\theta_{l, U S}=\right.$ 0.049). When we turn to Germany, that country experienced the reunification of 1989 as a deceleration of similar importance to the slowdown in the 1960s, taking the shape of a new downturn $\left(\gamma_{l, G E R}=-0.012\right)$.

Occurring in 1966, the break in the series of ideas (table B2) took on dimensions in the United States similar to the above mentioned researcher series trend break $\left(\gamma_{1, U S}=\right.$ -0.003), while it had a much greater impact in Germany $\left(\gamma_{1, G E R}=-0.009\right)$. Furthermore, there was a level break in the United Kingdom $\left(\theta_{1, U K}=0.032\right)$, in 1962, and another in the US $\left(\theta_{2, U S}=-0.034\right.$ ), coinciding with the first oil crisis, in 1973 (Jiménez and Sánchez, 2005).

Assuming that the use of this framework keeps on offering evidence against the unit root null hypothesis, we provide additional information in order to reinforce the validity of these assumptions. Therefore, we present and use (in Appendix C) the BaiPerron $(1998,2003 a, 2003 b)$ methodology as worthy complement in order to study the presence of breaks in the trend. A key feature of this procedure is that it allows testing for multiple breaks at unknown dates, so that it successfully estimates each break point by using a specific-to-general strategy in order to determine the number of breaks consistently. In that respect, it is of interest to highlight that the results reported in the main body of the text are not modified in any way by the application of this new set of statistics.

[While we mentioned above that the tests do no reject the hypothesis of a nonintegrated process, this could be elaborated upon further. The number of scientists and 
engineers obviously cannot keep growing forever at a constant rate. So saturation would suggest a non-integrative hypothesis, such as a logistic without trend breaks. We will test for this alternative on United States research intensity, as stated in Appendix D.]

Now that the reach and nature of the breaks have been seen, the (actual) rate of growth along the path of the steady state is compared with what it would have been (counterfactual), if the original path had not been interrupted by the structural change. Steady state growth rates were calculated from equations (6) and (7) using the estimated coefficients for the trend $(\hat{\beta})$ and lagged $y\left(\hat{c}_{j} \mathrm{~s}\right)$. The post break growth rates also incorporate the coefficient for the trend dummy variable $(\hat{\gamma})$. One of the main implications of the estimates is that the average rates of growth after the break of the 1960s depress the previous growth rates. Before that period, researchers and scientists hardly ever grew below a level of 5\% (table 3, panel A). Afterwards, only the United States and France grow at 3\%, while in Germany and the United Kingdom they scarcely rise beyond $1 \%$. As a consequence, the difference between average growth rates of the steady states is $\Delta y_{2}-\Delta y_{1}=-0.04$. In parallel fashion, the ratios of second period to first period $\Delta y_{2} / \Delta y_{1}$ range from 0.56 in the United States to 0.14 in Germany.

[Insert Table 3 around here]

The unequal intensity of the crisis in these two countries is reproduced in relation to the ideas (table 3, panel B). The difference between the growth rates of the final and initial steady-states, which is of -0.8 percentage points in the United States, reaches 4.6 points in Germany (ratios of 0.64 and 0.25 , respectively). Perhaps the most striking aspect of the process is that, after the structural change, new ideas grow almost at the 
same rhythm (1.4\% and 1.6\%) in both countries. In France and Great Britain, meanwhile, there is no evidence of breaks in the growth path.

The four countries exhibit features which evidence that both researchers and ideas moved onto a lower growth path after the break in the 1960s. To what point did the trends continue to descend afterwards? An intuitive approach consists in comparing their growth rates between 1950 and the first break year $\left(T_{B 1}\right)$ with the average between the last rupture $\left(T_{B m}\right)$ and 2001 . The steady-state growth rates were calculated for the baseline period and also for the final one in each country, and reported in table 4 . The last row provides an indication of the extent of the deceleration. As a general rule, the average annual growth rates of the final path were around $40 \%$ of those registered in the base path. The figures, along with the synchrony of the changes, reinforce the thesis of a strong correlation between processes of research intensity and discovery of new ideas in the United States. It is not sufficiently clear whether this occurs in the case of the European countries.

[Insert Table 4 around here]

The consequences of the changes in structure are of significance, bearing in mind the relationship between research, technical progress and growth. In the United States, at the rate of balanced growth prior to the break of 1967, the number of researchers and scientists doubled approximately every 14 years. Afterwards, the time required to do this had risen to over 23 years. What are the effects of the slowdown on the rhythms of advance of new ideas? From Jones (2002) and the observation of the difference between the initial and final steady-states, the ceteris paribus TFP would have managed to increase to a rate of $2.16 \%$ between 1976 and 2001 ; that is $58 \%$ more than the $1.37 \%$ 
actually registered. In the case of Germany, the potential increase is far more substantial, because there is a difference of 4.6 percentage points, above the meagre $1.57 \%$ achieved.

Did these countries depart from the original steady-state path? The answer appears to be affirmative, although a wider-reaching perspective would be required to respond to the question. Let us take a look at the researcher series: the ratio between growth rates after the last break and prior to the first scarcely surpasses a share of 0.50 on average. If, maintaining the numerator, the growth rate for the period between the first and second breaks is calculated on the denominator, the ratio is around $0.75-0.80$. In other words, it has nowhere near recovered the post-trend break standards of the 1960s. From a long-term perspective, such a supposition is far from clear.

Still, with the main focus on the trend breaks in R\&D process, to what degree are we dealing with definitive changes? The neoclassical model foresees a dynamic of transitory deviations from the balanced growth path. In the degree to which the vigorous growth observed up to the second half of the 1960 s reflects a transitional period, it could not possibly be sustained indefinitely. But our results also seem compatible with the fact that technological diffusion becomes increasingly difficult as the lagging countries draw closer to the frontier represented by the leader.

\section{CONCLUDING REMARKS}

Our study sets out to characterise possible breaks in the R\&D process in the United States and Europe, in the second half of the $20^{\text {th }}$ century. Several caveats need to be emphasised. First, the growth rate of TFP in the OECD countries has declined over the past decades, while the shares of GDP devoted to R\&D simultaneously show signs 
of stagnating. Second, the countries experience a trend and level break in the researcher series for the mid-1960s, with a slight variation in break year dates. The results as a whole also corroborate the thesis of new ideas slowdown, in the middle of the 1960s (coinciding, moreover, in the United States with the first oil crisis).

Third, the pre-break rates are higher than their post-break equivalents. In this connection, the United States and Germany appear to represent the end points in the range of incidence. In the former country, the slowdown involves a reduction in research growth rate, from 5.6\% until 1967, later dropping to 3.1\%. In Germany, the fall is far more dramatic, because it drops from $7.3 \%$ before 1963 to a mere $1 \%$ after that date. Parallel to these situations, the break in the idea stock growth path in 1966 meant that TFP was reduced by a third in the United States and by three quarters in Germany. Finally, the synchrony between researchers and ideas growth processes, in the US, reinforces the thesis of mutual interaction between them. Meanwhile correlation seems not to be as close among the European countries as it does in the US. 


\section{ACKNOWLEDGEMENTS}

The authors thank A. Colino for constructing the database and for his constant care in keeping it up to date. They are, likewise, grateful to A. Anchuelo, R. Myro, J. Pons, J. M. Sarabia and the referees for helpful comments and suggestions.

*V. Esteve acknowledges financial support from the Department of Business, Universities and Science of the Valencian Government, through the projects GRUPOS03/51 and GV05/030, as well as from the Department of Education and Science of Castilla-La Mancha's Government, through the project PBI-05-008.

†Corresponding author: Patricio Pérez, Departamento de Economía, Universidad de Cantabria, Avda. Los Castros, s/n, 39005, Santander, Spain. Fax: +34-942 201603 . email: perezp@unican.es 


\section{APPENDIX A: DATA SOURCES}

- GDP per Hour. The data for GDP at 1990's constant prices were calculated using Eurostat (Statistical appendix to European Economy). The values corresponding to the period 1950-1960 are based on the GDP Movement series provided by Maddison (1995b). Weekly working hours in non-agricultural activities were obtained from the Work Statistics Directories, published by the International Labour Organization (ILO), whilst it was necessary to use various issues of the OECD Labour Force Statistics in order to estimate some of the values for the UK.

- Human Capital. The data for average years of educational training for population over 25 years old come from De la Fuente and Doménech (2002) (updated to 2003).

- Engineers and Scientists Engaged in $R \& D$ activities. The source (National Science Board and OECD) is the same as in Jones (2002). The figures for Germany until 1989 are the sum of the old Federal and Democratic Republics. For the years prior to 1960 , it was assumed that the ratio of "research intensity" for the three European countries in relation to the US was the same in 1950 as in 1960 . This ratio was interpolated for the intermediate years and then multiplied by employment.

- People in work. The starting point is the total employment in 1960, obtained from OECD Labour Force Statistics. The series for the following years was obtained by applying to that number the rates of variation provided by Eurostat, in European Economy. In contrast, the series for the preceding years, 1950-1960, is the result of deducting the annual variations provided by Maddison (1995b) from the number of people employed in 1960.

- $R \& D$ expenditures. OECD, Main Science and Technology Indicators (various years), and Verspagen (1996) for dates prior to 1990. 


\section{APPENDIX B: TREND BREAK TESTS}

Table B1. Trend Break Tests Results: Researchers

\begin{tabular}{|c|c|c|c|c|}
\hline & USA & GER & FRA & UK \\
\hline \multicolumn{5}{|c|}{ Trend Breaks } \\
\hline$T_{B 1}$ & 1967 & 1989 & 1966 & 1968 \\
\hline$T_{B 2}$ & & 1963 & 1980 & \\
\hline \multicolumn{5}{|c|}{ Coefficients } \\
\hline \multirow[t]{2}{*}{$\hat{\mu}$} & 1.321 & 1.138 & 0.793 & 0.662 \\
\hline & $(6.80)$ & $(5.12)$ & $(4.65)$ & $(4.81)$ \\
\hline \multirow[t]{2}{*}{$\hat{\theta}_{1}$} & -0.049 & 0.080 & & 0.048 \\
\hline & $(4.24)$ & (3.43) & & $(3.36)$ \\
\hline \multirow[t]{2}{*}{$\hat{\theta}_{2}$} & & & 0.055 & \\
\hline & & & $(3.79)$ & \\
\hline \multirow[t]{2}{*}{$\hat{\beta}$} & 0.014 & 0.027 & 0.019 & 0.009 \\
\hline & $(4.33)$ & $(4.10)$ & $(3.80)$ & $(3.07)$ \\
\hline \multirow[t]{2}{*}{$\hat{\gamma}_{1}$} & -0.006 & -0.012 & -0.011 & -0.006 \\
\hline & $(2.73)$ & $(4.02)$ & $(4.32)$ & $(2.88)$ \\
\hline \multirow[t]{2}{*}{$\hat{\gamma}_{2}$} & & -0.011 & & \\
\hline & & (3.04) & & \\
\hline$\hat{c}_{1}$ & $1.17^{\mathrm{a}}$ & $1.02^{\mathrm{a}}$ & $0.92^{\mathrm{a}}$ & $1.11^{\mathrm{a}}$ \\
\hline$\hat{c}_{2}$ & $-0.35^{c}$ & $-0.39^{b}$ & -0.29 & $-0.30^{b}$ \\
\hline$\hat{c}_{3}$ & 0.19 & & $0.35^{\mathrm{c}}$ & \\
\hline$\hat{c}_{4}$ & $-0.35^{c}$ & & $-0.27^{b}$ & \\
\hline$\hat{c}_{5}$ & $0.32^{b}$ & & & \\
\hline$\hat{c}_{6}$ & $-0.24^{b}$ & & & \\
\hline
\end{tabular}

Notes: The asymptotic $t$-statistics are in parentheses. The letters ${ }^{\mathrm{a}},{ }^{\mathrm{b}}$ and ${ }^{\mathrm{c}}$ denote statistical significance at the 1,5 and $10 \%$ levels, respectively. 
Table B2. Trend Break Tests Results: Idea Stock

\begin{tabular}{|c|c|c|c|c|}
\hline & USA & GER & FRA & UK \\
\hline \multicolumn{5}{|c|}{ Trend Breaks } \\
\hline$T_{B 1}$ & 1966 & 1966 & & 1962 \\
\hline$T_{B 2}$ & 1973 & & & \\
\hline \multicolumn{5}{|c|}{ Coefficients } \\
\hline \multirow[t]{2}{*}{$\hat{\mu}$} & 0.553 & 0.068 & & 0.191 \\
\hline & $(4.21)$ & (1.99) & & $(3.00)$ \\
\hline \multirow[t]{2}{*}{$\hat{\theta}_{1}$} & & & & 0.032 \\
\hline & & & & $(3.08)$ \\
\hline \multirow[t]{2}{*}{$\hat{\theta}_{2}$} & -0.034 & & & \\
\hline & $(3.48)$ & & & \\
\hline \multirow[t]{2}{*}{$\hat{\beta}$} & 0.008 & 0.013 & & 0.002 \\
\hline & $(3.63)$ & $(3.55)$ & & $(2.30)$ \\
\hline \multirow[t]{2}{*}{$\hat{\gamma}_{1}$} & -0.003 & -0.009 & & \\
\hline & $(2.27)$ & $(3.46)$ & & \\
\hline$\hat{c}_{1}$ & $0.64^{\mathrm{a}}$ & $0.98^{\mathrm{a}}$ & & $0.79^{\mathrm{a}}$ \\
\hline$\hat{c}_{2}$ & & -0.10 & & \\
\hline$\hat{c}_{3}$ & & -0.22 & & \\
\hline$\hat{c}_{4}$ & & 0.24 & & \\
\hline$\hat{c}_{5}$ & & 0.16 & & \\
\hline$\hat{c}_{6}$ & & $-0.27^{b}$ & & \\
\hline
\end{tabular}

Notes: The asymptotic $t$-statistics are in parentheses. The letters ${ }^{\mathrm{a}},{ }^{\mathrm{b}}$ and ${ }^{\mathrm{c}}$ denote statistical significance at the 1,5 and 10\% levels, respectively. 


\section{APPENDIX C: TESTING FOR MULTIPLE STRUCTURAL BREAKS}

Earlier work by, e.g., Chow (1960) or Brown, Durbin and Evans (1975), focused on testing for structural change at a single known break data. More recently, however, the econometric literature has developed methods that allow estimating and testing for structural change at unknown break dates; see Andrews (1993) and Andrews and Ploberger (1994) for the case of a single structural change, and Andrews, Lee and Ploberger (1996), Liu, Wu and Zidek (1997) and Bai and Perron (1998, 2003a, 2003b) for the case of multiple structural changes.

A key feature of the Bai and Perron procedure is that it allows testing for multiple breaks at "unknown" dates, so that each break point is successively estimated by using a specific-to-general strategy in order to determine consistently the number of breaks. As an additional advantage, the Bai and Perron procedure allows investigating whether some or all the parameters of the estimated relationship have changed.

More specifically, Bai and Perron (1998, 2003a) consider a linear model with $m$ multiple structural changes (i.e., $m+1$ regimes), such as:

$$
\begin{gathered}
y_{t}=z_{t}^{\prime} \boldsymbol{\delta}_{1}+u_{t}, \quad t=1, \ldots, T_{1}, \\
y_{t}=z_{t}^{\prime} \boldsymbol{\delta}_{2}+u_{t}, \quad t=T_{1}+1, \ldots, T_{2}, \\
\ldots \\
y_{t}=z_{t}^{\prime} \boldsymbol{\delta}_{m+1}+u_{t}, \quad t=T_{\mathrm{m}}+1, \ldots, T,
\end{gathered}
$$

where $y_{t}$ is the observed dependent variable at time $t, Z_{t}(q \times 1)$ is a matrix of regressors, $\delta_{j}(j=1, \ldots, m+1)$ is the corresponding vector of coefficients and $u_{t}$ is the error term at time $t$. The indices $\{\bar{Z}\}$, i.e., the break points, are explicitly treated as unknown. 
The issue of testing for structural changes is also considered under very general conditions on the data and the errors. The Bai and Perron tests are based upon an information criterion in the context of a sequential procedure, and allows one to find the numbers of breaks implied by the data, as well as estimating the timing and the confidence intervals of the breaks, and the parameters of the processes between breaks. This procedure, on the other hand, is not computationally excessive, allowing for the computation of the estimates using at most least-squares operations of order $O\left(T^{2}\right)$ for any number of structural changes $m$, unlike a standard grid search procedure which would require least squares operation of order $O\left(T^{m}\right)$.

Bai and Perron $(1998,2003 a)$ propose three methods to determine the number of breaks: a sequential procedure, SP (Bai and Perron, 1998); the Schwarz modified criterion, LWZ (Liu, Wu and Zidek, 1997); and the Bayesian information criterion, BIC (Yao, 1988). Finally, the authors suggest several statistics in order to identify the break points:

- The $\sup F_{T}(k)$ test, i.e., a sup $F$-type test of the null hypothesis of no structural break $(m=0)$ versus the alternative of a fixed (arbitrary) number of breaks $(m=k)$.

- Two maximum tests of the null hypothesis of no structural break $(m=0)$ versus the alternative of a unknown number of breaks given some upper bound $M(1 \leq m \leq M)$, i.e., $U D$ max test, an equal weighted version, and WD max test, with weights that depend on the number of regressors and the significance level of the test.

- The $\sup F_{T}(l+1 \mid l)$ test, i.e., a sequential test of the null hypothesis of $l$ breaks versus the alternative of $l+1$ breaks.

The results of using the tests are shown in Table $\mathrm{C} 1$. We have applied the Bai and Perron procedures with a constant, a trend and one lag of dependent variable as regressor, allowing up to 3 breaks, and constraining each segment to have at least 10 
observations. The sup $F_{T}(k)$ tests are significant for all series. The $U D$ max and WD max are also highly significant. So, at least one break is present. In the case of the researcher and scientist series the sequential procedure (using a 5\% significance level) selects two breaks for Germany and France, and one break for the US and Great Britain. In the case of the idea stock series the sequential procedure (using a 5\% significance level) selects two breaks in US, and one break for Germany and Great Britain; no breaks are detected in the series of ideas for France.

[Insert Table C1 around here]

Thus, the Bai and Perron procedure depicts trend breaks that fit properly the shifts provided above in the text, both in the researcher and in the idea stock series, except for one. It detects indeed a trend break in German idea stock in 1986 out of keeping with the Perron (1997) and Ben-David and Papell (2000) procedures. However it is worthy of attention to highlight that the later point to a likely level break that year. Therefore, the new estimates reinforce as a whole the results we get in table 2. The conclusion reached again is that there are structural breaks in the series around the midsixties. Nonetheless, we recognise that the GLS tests present better properties (size and power) than those of OLS tests. 
Table C1. Tests for Multiple Structural Breaks in Lineal Models:

the Bai and Perron Procedure

\begin{tabular}{|c|c|c|c|c|}
\hline \multicolumn{5}{|c|}{ A) Researchers and scientists } \\
\hline$\overline{\text { Test }}$ & $\mathrm{USA}^{f}$ & $\mathrm{GER}^{f}$ & FRA $^{f}$ & $\mathrm{UK}^{f}$ \\
\hline$\overline{\sup } F_{T}(1)^{a, c, e}$ & $34.55^{* * *}$ & $13.97^{* *}$ & $23.62^{* * *}$ & $18.25^{* * *}$ \\
\hline $\sup F_{T}(2)^{a, c, e}$ & $26.27^{* * *}$ & $12.68^{* * *}$ & $24.55^{* * *}$ & $23.20^{* * *}$ \\
\hline $\sup F_{T}(3)^{a, c, e}$ & $21.29^{* * *}$ & $17.88^{* * *}$ & $19.44^{* * *}$ & $15.97^{* * *}$ \\
\hline$U D \max$ & $34.45^{* * *}$ & $17.88^{* * *}$ & $24.55^{* * *}$ & $23.20^{* * *}$ \\
\hline$W D \max$ & $34.4^{* * *}$ & $29.80^{* * *}$ & $32.42^{* * *}$ & $30.63^{* * *}$ \\
\hline $\sup F_{T}(2 \mid 1)^{c, e}$ & $13.93^{* *}$ & $20.83^{* * *}$ & $14.13^{* *}$ & $15.53^{* * *}$ \\
\hline $\sup F_{T}(3 \mid 2)^{c, e}$ & 10.70 & $22.86^{* * *}$ & 6.56 & 2.54 \\
\hline$l^{b}$ & 1 & 2 & 2 & 1 \\
\hline$\hat{T}_{1}^{d}$ & 1966 & 1965 & 1964 & 1967 \\
\hline$\hat{T}_{2}^{d}$ & - & 1988 & 1979 & - \\
\hline$\hat{T}_{3}^{d}$ & - & & - & - \\
\hline
\end{tabular}

B) Idea stock

\begin{tabular}{llll}
\hline Test & $\mathrm{USA}^{g}$ & $\mathrm{GER}^{f}$ & $\mathrm{UK}^{f}$ \\
\hline $\sup F_{T}(1)^{a, c, e}$ & $19.05^{* * *}$ & $19.30^{* * *}$ & $11.62^{* * *}$ \\
$\sup F_{T}(2)^{a, c, e}$ & $18.18^{* * *}$ & $16.92^{* * *}$ & $8.91^{*}$ \\
$\sup F_{T}(3)^{a, c, e}$ & $12.62^{* * *}$ & $11.12^{* * *}$ & $8.01^{* *}$ \\
$U D \max$ & $19.05^{* * *}$ & $19.30^{* * *}$ & $11.62^{* *}$ \\
$W D \max$ & $23.89^{* * *}$ & $22.34^{* * *}$ & $12.33^{* *}$ \\
$\sup F_{T}(2 \mid 1)^{c, e}$ & $16.08^{* *}$ & 8.00 & 6.35 \\
$\sup F_{T}(3 \mid 2)^{c, e}$ & 4.72 & 1.51 & 3.86 \\
$l^{b}$ & 2 & 1 & 1 \\
$\hat{T}_{1}^{d}$ & 1960 & 1986 & 1961 \\
$\hat{T}_{2}^{d}$ & 1972 & - & - \\
$\hat{T}_{3}^{d}$ & - & - & - \\
\hline
\end{tabular}


Notes:

${ }^{a}$ The sup $F_{T}(k)$ tests and the confidence intervals allow for the possibility of serial correlation in the disturbances. The heteroskedasticity and the autocorrelation consistent covariance matrix is constructed following Andrews (1991) and Andrews and Monahan (1992) using a quadratic kernel with automatic bandwidth selection based on an AR(1) approximation. The residuals are pre-whitened using a VAR(1).

${ }^{b} l$ is the number of breaks obtained from the sequential procedure (SP) at the $5 \%$ size for the sequential test $\sup F_{T}(l+1 \mid l)$.

${ }^{c}$ In the implementation of the procedure, we allowed up to three breaks $(M=3)$ and we use a trimming $\varepsilon=0.20$ which corresponds to each segment having at least 10 observations.

${ }^{d} T_{i=1,2}$ are the break dates estimated.

${ }^{e} \mathrm{~A}^{*},{ }^{* *}$ and ${ }^{* * *}$ denote significance at the $10 \%, 5 \%$ and $1 \%$ levels, respectively.

${ }^{f}$ We apply the procedure with the dependent variable, $y_{t}$, a constant and one lag of $y_{t}$ as regressor $\left[z_{t}=\left\{1, y_{t-1}\right\}\right]$.

${ }^{g}$ We apply the procedure with the dependent variable, $y_{t}$, a constant, a trend and one lag of $y_{t}$ as regressor $\left[z_{t}=\left\{1, t, y_{t-1}\right\}\right]$. 


\section{APPENDIX D: TESTING FOR A LOGISTIC ALTERNATIVE}

The logistic curve is given by the equation:

$$
l_{A}=\frac{l_{A \max }}{1+b e^{-c T}},
$$

where $l_{A}$ is research intensity (which to a significant extent consists of the share of researchers in the labour population), $l_{\text {Amax }}$ is the (known) saturation level and $T$ is the number of observations. The above equation is an $S$-shaped curve, which may be used to represent the research intensity that ceteris paribus will someday saturate the market. Now, by taking the natural logarithm of both sides and rearranging terms, this leads to:

$$
\log \left(\frac{l_{A \max }}{l_{A t}}-1\right)=\log b-c T_{t}+\varepsilon_{t}
$$

where the disturbance term $\varepsilon_{t}$ is assumed to be serially uncorrelated and orthogonal to the explanatory variables. The share of the population that works in research is obtained by setting $l_{A}=L_{A} / L$. Suppose the stocks $K$ and $A$ growth at constant rates. In this case, substituting for $l_{Y}=1-l_{A}$ in equation (10) from Jones (2002), output per worker $y_{t}=Y_{t}$ / $L_{t}$ can be decomposed as:

$$
y_{t}^{*}=\left(\frac{s_{K t}^{*}}{n+g_{k}+d}\right)^{\frac{\alpha}{1-\alpha}}\left(1-l_{A t}\right) h_{t}\left(\frac{\delta}{g_{A}}\right)^{\frac{\gamma}{\lambda}}\left(l_{A t} L_{t}^{*}\right)^{\gamma},
$$

where $k \equiv K / L$ and $\gamma \equiv \frac{\sigma}{1-\alpha} \frac{\lambda}{1-\phi}$. Notice that $l_{A} L$ is just $H_{A}$. Here, $g_{x}$ represents the constant growth rate of some variable $x$ and an asterisk denotes a quantity that is growing at a constant rate. To maximise output per worker along a balanced growth path, take the derivative respect to $l_{A}$ :

$$
\frac{\partial y^{*}(t)}{\partial l_{A}}=B \frac{\partial\left(1-l_{A}\right) l_{A}^{\gamma}}{\partial l_{A}}
$$


where

$$
B=\left(\frac{s_{K t}^{*}}{n+g_{k}+d}\right)^{\frac{\alpha}{1-\alpha}} h_{t}\left(\frac{\delta}{g_{A}}\right)^{\frac{\gamma}{\lambda}} L_{t}^{* \gamma} .
$$

The maximum occurs when the derivative is equal to zero, and $\frac{\partial y^{*}(t)}{\partial l_{A}}=0$ implies that

$$
l_{A}^{*}\left[1-\left(1-l_{A}^{*}\right) \gamma \frac{1}{l_{A}^{*}}\right]=0 .
$$

Solving the equation for $l_{A}^{*}$ then (in addition to the trite $l_{A}^{*}=0$ ) reveals:

$$
l_{A}^{*}=\frac{\gamma}{1+\gamma} .
$$

Jones (2002) restricted estimates of $\gamma$ for the US between 1950 and 1993 range from 0.178 when $\lambda=1$ to 0.076 when $\lambda=0.25$, with an intermediate value of $\gamma=$ 0.123. With this parameter value, we have $l_{A}^{*}=0.109$.

[Insert Table D1 around here]

Table D1 reports estimates from upper regressions for USA, setting $l_{A \max }=l_{A}^{*}$. They are a mixture of good news and bad news. Looking at the good news first, we see that the specification appears to be statistically sensitive to the different sample periods. Both coefficients are well determined by conventional standards. Now look at the bad news. The earlier 1950-1967 and the later 1973-2001 periods yield $c$ coefficients of the same (negative) sign, while the estimate for the intermediate 1967-1973 period changes to a positive one. The hypothesis of stability is decisively rejected for the Chow test, the $F$ statistic registering at 233.1, which far exceeds any standard critical value. The tabled critical value ( $1 \%$ significance) is 5.10 , so, consistent with our expectations, we reject the hypothesis that the coefficient vectors are the same in the three periods. 
Table D1. Time Series Estimates of Research Intensity in US

\begin{tabular}{lrrrr}
\hline \hline Coefficients & $1950-2001$ & $1950-1967$ & $1967-1973$ & $1973-2001$ \\
\hline $\log b$ & 1.16 & 1.30 & 0.68 & 1.22 \\
& $(75.60)$ & $(132.08)$ & $(51.66)$ & $(89.69)$ \\
$c$ & -0.006 & -0.021 & 0.015 & -0.007 \\
& $(11.45)$ & $(23.09)$ & $(23.73)$ & $(19.65)$ \\
$R^{2}$ & 0.72 & 0.97 & 0.99 & 0.93 \\
Standard error & 0.055 & 0.020 & 0.003 & 0.016 \\
Sum of squares & 0.150 & 0.006 & 0.000 & 0.007 \\
\hline \multicolumn{2}{l}{ Note: Newey-West robust $t$-statistics are in parentheses. }
\end{tabular}




\section{REFERENCES}

Abubader, S. (2002), Institutional changes and breakpoints in Israeli trade, Applied Economics, 34, 1893-1901.

Andrews, D. W. K. (1991) Heteroskedasticity and Autocorrelation Consistent Covariance Matrix Estimation, Econometrica, 59, 817-858.

_ (1993) Tests for Parameter Instability and Structural Change with Unknown Change Point, Econometrica, 61, 821-856.

Andrews, D. W. K. and Monahan, J. C. (1992) An Improved Heteroskedasticity and Autocorrelation Consistent Covariance Matrix Estimator, Econometrica, 60, 953966.

Andrews, D. W. K. and Ploberger, W. (1994) Optimal Tests when a Nuisance Parameter is Present Only Under the Alternative, Econometrica, 62, 1383-1414.

Andrews, D. W. K., Lee, I. and W. Ploberger (1996) Optimal Changepoint Tests for Normal Lineal Regression, Econometrica, 64, 9-38.

Atella, V. and Quintieri, B. (2001) Do R\&D expenditures really matter for TFP?, Applied Economics, 33, 1385-1389.

Atkings, F. J. and M. Chan (2004), Trend breaks and the fisher hypothesis in Canada and the United States, Applied Economics, 36, 1907-1913.

Bai, J. and Perron, P. (1998) Estimating and Testing Linear Models with Multiple Structural Changes, Econometrica, 66, 47-78.

_ (2003a) Computation and Analysis of Multiple Structural Change Models, Journal of Applied Econometrics, 18, 1-22.

_ (2003b) Critical Values for Multiple Structural Change Tests, Econometrics Journal, 6, 75-2-78. 
Ben-David, D. and Papell, D. H. (1995) The Great Wars, the Great Crash, and the Unit Root Hypothesis: Some New Evidence About an Old Stylised Fact, Journal of Monetary Economics, 36, 453-475.

_ (1998) Slowdowns and Meltdowns: Postwar Evidence from 74 Countries, Review of Economics and Statistics, 80, 561-571.

_ (2000) Some Evidence on the Continuity of the Growth Process among the G7 Countries, Economic Inquiry, 2, 320-330.

Ben-David, D., Lumsdaine, R. L. and Papell, D. H. (2003) Unit roots, postwar slowdowns and long run growth: Evidence from two structural breaks, Empirical Economics, 28, 303-319.

Bils, M. and Klenow, P. J. (2000) Does Schooling Cause Growth?, American Economic Review, 90, 1160-1183.

Brown, R. L., Durbin, J. and Evans, J. M. (1975) Techniques for Testing the Constancy of Regression Relationships over Time, Journal of Royal Statistical Society Series $B, 37,149-163$.

Campbell, J. Y. and Perron, P. (1991) Pitfalls and opportunities: What macroeconomists should know about unit roots, NBER Macroeconomics Annual, 141-201.

Chow, G. C. (1960) Tests for Inequality Between Sets of Coefficients in Two Linear Regressions, Econometrica, 28, 591-605.

De la Fuente, A. and Doménech, R. (2002) Human Capital in Growth Regressions: How Much Difference Does Data Quality Make?, DT 2002-02, Ministerio de Hacienda. Griliches, Z. (1990) Patent Statistics and Economic Indicators: A Survey, Journal of Economic Literature, 18, 1661-1707.

_ (1994) Productivity, R\&D, and the Data Constraint, American Economic Review, 84, 1-23. 
Harberger, A. and Wisecarver, D. (1977) Private and social rates of return to capital in Uruguay, Economic Development and Cultural Change, 25, 411-445.

Harvey, D. I. and Mills, T. C. (2005) Evidence for common features in G7 macroeconomic time series, Applied Economics, 37, 165-175.

Jiménez-Rodríguez, R. and M. Sánchez (2005), Oil price shocks and real GDP growth: empirical evidence for some OECD countries, Applied Economics, 37, 201-228.

Jones, Ch. I. (1995) R\&D Based Models of Economic Growth, Journal of Political Economy, 103, 759-784.

_ (2002) Sources of U.S. Economic Growth in a World of Ideas, American Economic Review, 92, 220-239.

Liu, J., Wu, S. and Zideck, J. V. (1997) On Segmented Multivariate Regressions, Statistica Sinica, 7, 497-525.

Lumsdaine, L. R. and Papell, D. H. (1997) Multiple Trend Breaks and the Unit Root Hypothesis, Review of Economics and Statistics, 79, 212-218

Keely, L. C. and Quah, D. (1998) Technology in growth. Centre for Economic Performance, Discussion paper no. 391.

Maddison, A. (1995a) Explaining the economic performance of nations: essays in time and space. Economists of the Twentieth Century Series. Aldershot, Hants: Edward Elgar.

_ (1995b) Monitoring the world economy, 1820-1992. Paris: Organisation for Economic Cooperation and Development.

Perron, P. (1989) The great crash, the oil price shock, and the unit-root hypothesis, Econometrica, 57, 1361-1401.

_(1997) Further evidence on breaking trend functions in macroeconomic variables, Journal of Econometrics, 80, 355-385. 
Romer, P. M. (1990) Endogenous Technological Change, Journal of Political Economy, 98, 71-102.

_ (2000) Should the Government Subsidize Supply or Demand in the Market for Scientists and Engineers?, NBER working paper no. 7723.

Sen, A. (2004) Are US macroeconomic series difference stationary or trend-break stationary?, Applied Economics, 36, 2025-2029.

Verspagen, B. (1996) Technology indicators and economic growth. In Bart Van Ark and Nicholas Crafts (ed.), Quantitative Aspects of Post-War European Growth, pp. 215-243. Cambridge: Cambridge University Press.

Vogelsang, T. J. and Perron, P. (1998) Additional tests for a unit-root allowing for a break in the trend function at a unknown time, International Economic Review, 39, 1073-1100.

Yao, Y. C. (1988) Estimating the Number of Change-Points via Schwarz's Criterion, Statistics and Probability Letters, 6, 181-189. 
Table 1. Total R\&D Expenditures as a Fraction of GDP

\begin{tabular}{cccccc}
\hline Year & USA & GER & FRA & JAP & UK \\
\hline 1963 & & 0.014 & 0.016 & 0.015 & \\
1967 & $0.021^{\mathrm{a}}$ & 0.018 & 0.021 & 0.016 & $0.015^{\mathrm{a}}$ \\
1970 & 0.027 & 0.021 & 0.019 & 0.018 & \\
1975 & 0.023 & 0.022 & 0.018 & 0.020 & $0.013^{\mathrm{a}}$ \\
1981 & 0.025 & 0.024 & 0.019 & 0.023 & 0.024 \\
1986 & 0.029 & 0.027 & 0.022 & 0.027 & 0.023 \\
1990 & 0.028 & 0.027 & 0.024 & 0.031 & 0.022 \\
1995 & 0.025 & 0.026 & 0.023 & 0.030 & 0.020 \\
2001 & 0.028 & 0.025 & 0.022 & 0.031 & 0.019 \\
\hline Average & 0.026 & 0.021 & 0.019 & 0.022 & 0.019 \\
\hline B & & & & & \\
\hline
\end{tabular}

${ }^{\mathrm{a}}$ Business R\&D expenditures as a fraction of GDP.

Sources: OECD (various years) Main Science and Technology Indicators; Verspagen (1996). 
Table 2. Sequential Trend Break Tests

\begin{tabular}{|c|c|c|c|c|}
\hline \multicolumn{5}{|c|}{ A) Researchers and scientists } \\
\hline Country & Break & Year & $\operatorname{Sup} F_{t}$ & $k$ \\
\hline United States & 1 & 1967 & 18.49 & 6 \\
\hline \multirow[t]{2}{*}{ Germany } & 1 & 1989 & 16.15 & 8 \\
\hline & 2 & 1963 & 13.21 & 2 \\
\hline \multirow[t]{2}{*}{ France } & 1 & 1966 & 22.48 & 4 \\
\hline & 2 & 1980 & 29.29 & 4 \\
\hline United Kingdom & 1 & 1968 & 16.18 & 2 \\
\hline \multicolumn{5}{|l|}{ B) Idea stock } \\
\hline Country & Break & Year & $\operatorname{Sup} F_{t}$ & $k$ \\
\hline \multirow[t]{2}{*}{ United States } & 1 & 1966 & 21.61 & 6 \\
\hline & 2 & 1973 & 14.64 & 1 \\
\hline Germany & 1 & 1966 & 24.00 & 6 \\
\hline United Kingdom & 1 & 1962 & 18.93 & 1 \\
\hline
\end{tabular}

\section{Critical values}

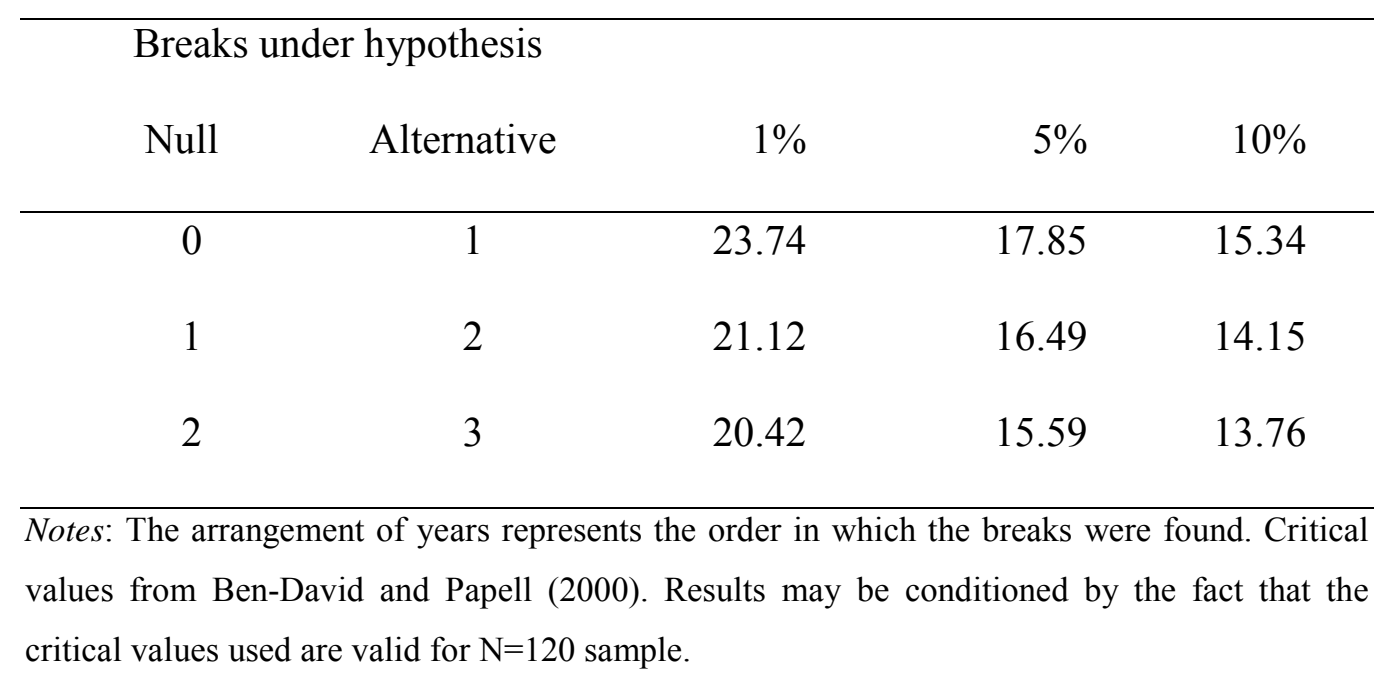


Table 3. Pre- and Post-Break Steady-States

\begin{tabular}{|c|c|c|c|c|}
\hline \multicolumn{5}{|c|}{ A) Researchers and scientists } \\
\hline Coefficients & USA & GER & FRA & UK \\
\hline$\beta$ & 0.014 & 0.027 & 0.019 & 0.009 \\
\hline$\gamma_{1}$ & -0.006 & -0.012 & -0.011 & -0.006 \\
\hline$\gamma_{2}$ & & -0.011 & & \\
\hline \multirow[t]{2}{*}{$\Delta \mathrm{y}_{1, \mathrm{t}<\mathrm{TB}}$} & 0.056 & 0.073 & 0.067 & 0.048 \\
\hline & $(10.86)$ & (13.89) & $(17.18)$ & $(6.85)$ \\
\hline \multirow[t]{2}{*}{$\Delta \mathrm{y}_{2, \mathrm{t}}>\mathrm{TB}$} & 0.031 & 0.010 & 0.030 & 0.014 \\
\hline & $(29.34)$ & (1.43) & $(8.02)$ & $(5.84)$ \\
\hline$\Delta \mathrm{y}_{2}-\Delta \mathrm{y}_{1}$ & -0.025 & -0.063 & -0.038 & -0.034 \\
\hline$\frac{\Delta y_{2}}{\Delta y_{1}}$ & 0.56 & 0.14 & 0.44 & 0.29 \\
\hline
\end{tabular}

B) Idea stock

\begin{tabular}{|c|c|c|c|c|}
\hline Coefficients & USA & GER & FRA & UK \\
\hline$\beta$ & 0.008 & 0.013 & & \\
\hline$\gamma_{1}$ & -0.003 & -0.009 & & \\
\hline \multirow[t]{2}{*}{$\Delta \mathrm{y}_{1 . \mathrm{t}<\mathrm{TB}}$} & 0.022 & 0.062 & & \\
\hline & (11.76) & $(8.31)$ & & \\
\hline \multirow[t]{2}{*}{$\Delta \mathrm{y}_{2 . \mathrm{t}}>\mathrm{TB}$} & 0.014 & 0.016 & & \\
\hline & (12.87) & $(4.43)$ & & \\
\hline$\Delta \mathrm{y}_{2}-\Delta \mathrm{y}_{1}$ & -0.008 & -0.046 & & \\
\hline$\frac{\Delta y_{2}}{\Delta y_{1}}$ & 0.64 & 0.25 & & \\
\hline
\end{tabular}

Notes: The asymptotic $t$-statistics of $\Delta \mathrm{y}_{1}$ and $\Delta \mathrm{y}_{2}$, calculated using the delta method, are in parentheses. No trend breaks are detected in the series of ideas for France and the United Kingdom. The most likely trend breakpoints for idea stock in both countries are 1966 and 1973, respectively. 
Table 4. Growth Rate Comparison of Steady States

\begin{tabular}{|c|c|c|c|c|}
\hline \multicolumn{5}{|c|}{ A) Researchers and scientists } \\
\hline & USA & GER & FRA & UK \\
\hline Break year $\left(T_{B}\right)$ & 1967 & $\begin{array}{l}1963 \\
1989\end{array}$ & 1966 & 1968 \\
\hline Pre- $T_{B 1} \quad$ (a) & 7.4 & 8.0 & 7.3 & 6.3 \\
\hline Post- $T_{B m}$ (b) & 2.6 & 3.4 & 3.6 & 2.7 \\
\hline $\operatorname{Ratio}(c=b / a)$ & 0.35 & 0.43 & 0.49 & 0.42 \\
\hline
\end{tabular}

B) Idea stock

\begin{tabular}{lcccc}
\hline & USA & GER & FRA & UK \\
\hline Break year $(i)$ & 1966 & 1966 & \\
Pre- $T_{B 1} \quad$ (a) & 2.4 & 6.3 & \\
${\text { Post- } T_{B m} \text { (b) }}_{\text {Ratio }(\mathrm{c}=\mathrm{b} / \mathrm{a})}$ & 0.44 & 1.1 & 0.28 &
\end{tabular}

Notes: Average annual rates, in percentages. No trend breaks are detected in the series of ideas for France and the United Kingdom. 
FRANCE. Break Year: 1966

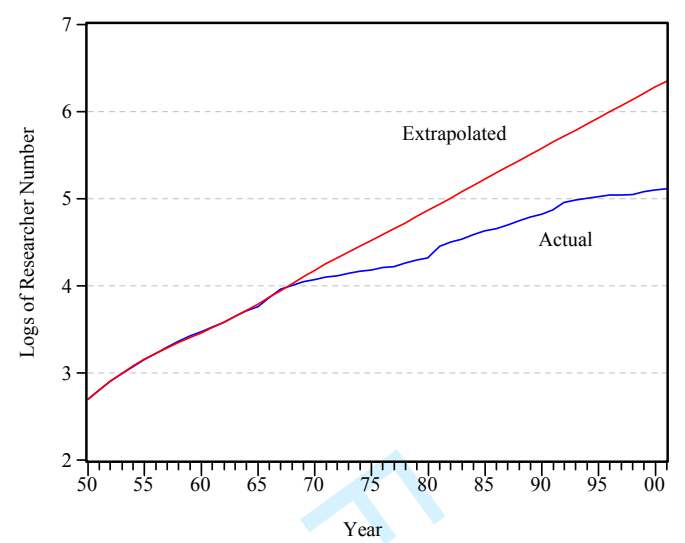

UNITED KINGDOM. Break Year: 1968

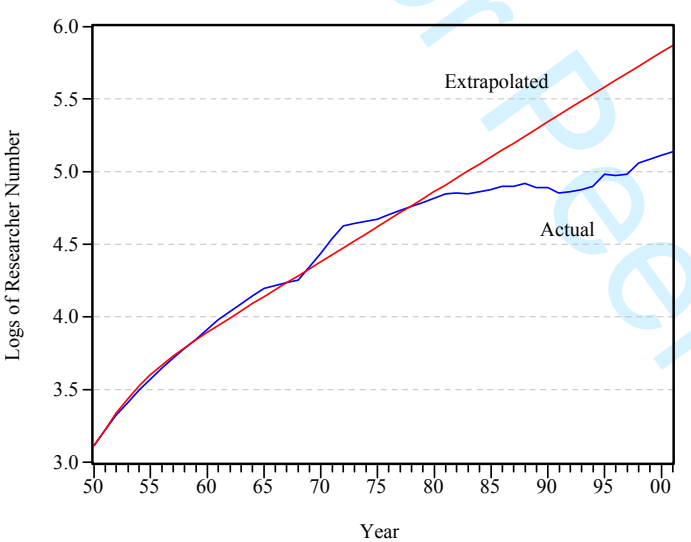

GERMANY. Break Year: 1989

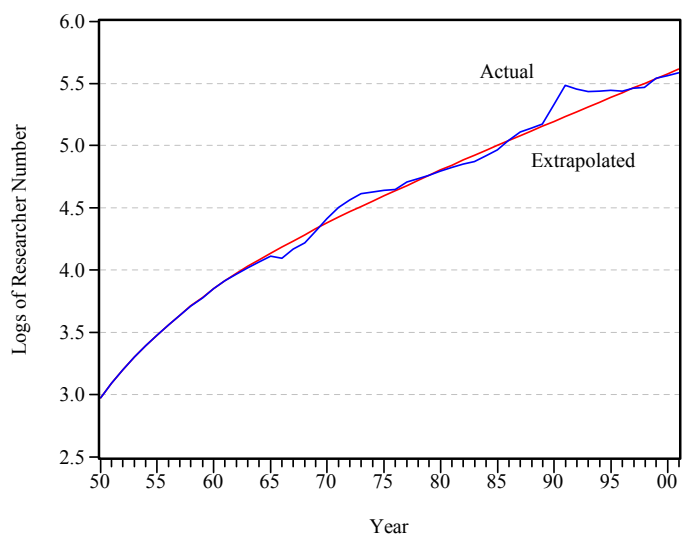

UNITED STATES. Break Year: 1967

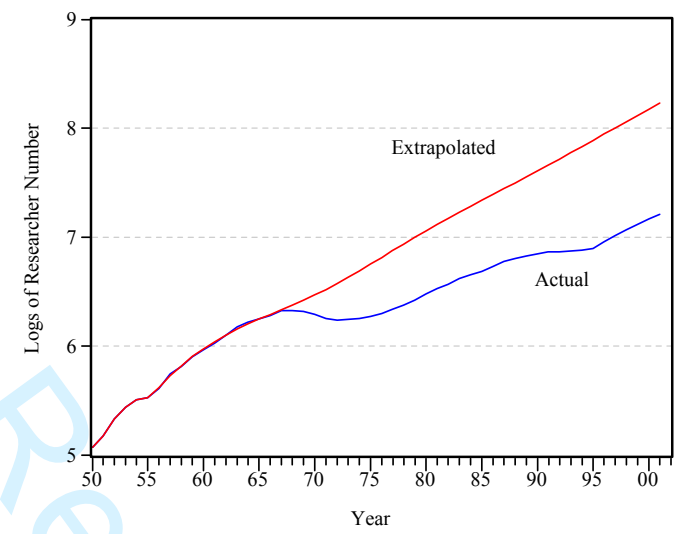

Figure 1. Slowdown in R\&D Series: 1950-2001. Trend break years are above the panels. The scales of the panels are not the same. 

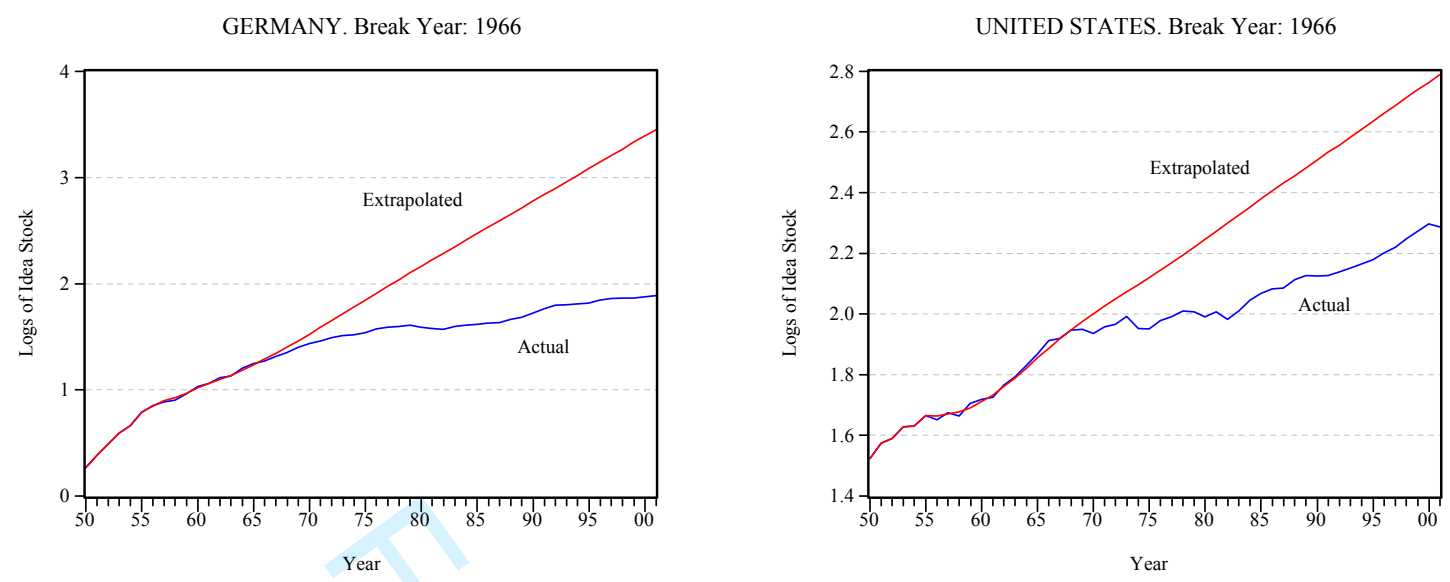

Figure 2. Slowdown in Idea Stock: 1950-2001. Trend break years are above the panels. No breaks are detected in the series of ideas for France and the United Kingdom. The scales of the panels are not the same. 